\title{
Spatial analysis of cerebral palsy in children and adolescents and its association with health vulnerability
}

\author{
Marcus Valerius da Silva Peixoto, ${ }^{1,2,3}$ Andrezza Marques Duque, ${ }^{2}$ \\ Allan Dantas dos Santos, ${ }^{2}$ Shirley Verônica Almeida Melo Lima, ${ }^{2}$ Társilla Pereira Gonçalves, ${ }^{3}$ \\ Ana Paula de Souza Novais, ${ }^{3}$ Susana de Carvalho ${ }^{3}$ Silvia Maria Voci, ${ }^{4}$ \\ Karina Conceição Gomes Machado de Araújo, ${ }^{5}$ Marco Antônio Prado Nunes ${ }^{2}$
}

\author{
${ }^{1}$ Federal University of Sergipe; ${ }^{2}$ Postgraduate program in health sciences, Federal University of Sergipe; \\ ${ }^{3}$ Speech Therapy and Audiology department, Federal University of Sergipe; ${ }^{4}$ Nutrition department, Federal \\ University of Sergipe; ${ }^{5}$ Postgraduate program in health sciences, Federal University of Sergipe, São \\ Cristóvão-SE, Brazil
}

\begin{abstract}
Cerebral Palsy (CP) is commonly associated with low socioeconomic status. Use of spatial statistics and a Geographic Information Systems (GIS) are scarce and may contribute to the understanding of $\mathrm{CP}$ in a social context. To that end a spatial analysis of $\mathrm{CP}$ in children and adolescents was performed to analyze the association of $\mathrm{CP}$ with levels of vulnerability in a city (Aracaju, Sergipe) in north-eastern Brazil. In addition, an ecological study was conducted with data obtained from a populationbased survey and secondary data. Exploratory spatial data analysis and linear regression were used. A total of $288 \mathrm{CP}$ cases were identified, with a prevalence of 1.65/1,000 and differences among city neighbourhoods ranging from $0-4 / 1,000$. The mean age of cases studied was 9 years 1 month, with a standard deviation of 5
\end{abstract}

Correspondence: Karina Conceição Gomes Machado de Araújo, Federal University of Sergipe, Marechal Rondon Avenue, São Cristóvão-SE, Zip code 49100-000, Brazil.

E-mail: karinaconceicaoaraujo@gmail.com

Key words: Cerebral Palsy; Epidemiology; Prevalence; Spatial Analysis; Child Health; Brazil.

Ethical approval: The study was approved (number 1,177,455) by the Research Ethics Committee of the Federal University of Sergipe and follows the ethical principles of the National Commission for Research Ethics (CONEP) and the Declaration of Helsinki. All adults responsible for the participants agreed and signed an informed consent form.

Conflict of Interest: The Authors declare no potential conflict of interests.

Received for publication: 27 September 2019.

Accepted for publication: 18 February 2020.

(C) Copyright: the Author(s), 2020

Licensee PAGEPress, Italy

Geospatial Health 2020; 15:817

doi:10.4081/gh.2020.817

This article is distributed under the terms of the Creative Commons Attribution Noncommercial License (CC BY-NC 4.0) which permits any noncommercial use, distribution, and reproduction in any medium, provided the original author(s) and source are credited. years 2 months. Most study subjects with cerebral palsy (163) were male $(56.4 \%)$. The distribution of $\mathrm{CP}$ in the study population was not homogeneous throughout the territory. Some areas had clusters, with more cases associated with areas of high vulnerability. Spatial data analysis using GIS was useful to gain an epidemiological understanding of CP distribution that can guide decisionmaking with respect to production, distribution, and regulation of health goods as well as services at the local level.

\section{Introduction}

The epidemiological characteristics of Cerebral Palsy (CP) have been studied using different perspectives and methods. This is due to the impact of $\mathrm{CP}$ on patient health, as it is the main cause of physical disability and permanent sequelae in children. However, many aspects of CP are not completely known and deserve further clarification (Graham et al., 2016). The worldwide prevalence of CP is 2-3/1,000 live births and premature birth and low birth weight are among the main causes (McIntyre et al., 2013; Oskoui et al., 2013; Colver et al., 2014). Researchers report that the association between lower Socio-Economic Status (SES) and low birth weight may increase CP risk (Solaski et al., 2014). Another hypothesis is that postnatal lesions are more often associated with socioeconomic deprivation than with other factors (Dolk et al., 2010). The use of composite indicators of deprivation or social disadvantage has been a methodological alternative for measuring SES (Dolk et al., 2010; Oskoui et al., 2016).

Geospatial analyses are commonly used for analyzing communicable diseases (Kirby et al., 2017), with increasing use for non-communicable diseases and other health conditions such as pregnancy. Studies describing patterns of spatial distribution for congenital disabilities have aimed at understanding events, identifying risk areas, and formulating policies for prevention and care of disease in priority areas (Chi et al., 2008; de Miranda et al., 2014; Liao et al., 2016). The use of spatial statistics and a geographical information systems (GIS) approach may contribute to the understanding of $\mathrm{CP}$ in a social context. This study aimed to perform a spatial analysis of CP in children and adolescents and to correlate the presence of CP with levels of health vulnerability in north-eastern Brazil. 


\section{Materials and Methods}

\section{Study Area}

This ecological study used data obtained from a populationbased survey between 2016 and 2017 in Aracaju, capital of the State of Sergipe in north-eastern Brazil. Aracaju has 39 neighbourhoods, 764 census tracts and no rural areas and occupies an area of $181.90 \mathrm{~km}^{2}$ with an estimated population of 623,766 inhabitants and a population density of 3140.70 inhabitants $/ \mathrm{km}^{2}$ according to data from the Brazilian Institute of Geography and Statistics (IBGE) (IBGE, 2018). Primary health care services cover $93 \%$ of the population, with 44 healthcare units and 144 primary care teams.

\section{Data collection}

The data were collected between June 2016 and December 2017. The researchers provided training for key informants from the primary care health teams to identify addresses of children and adolescents with CP linked to each health service. After the training, the researchers performed house visits collecting data by applying a structured questionnaire developed by the researchers. The survey was also conducted in the only specialized public rehabilitation service, in order to reach the largest number of participants. Government data from the education and health sectors were also used. Data on children and adolescents with CP, mothers' names and dates of birth were cross-checked to avoid duplication. The flowchart in Figure 1 shows the data production process.

The research team collected the data in the homes of people with $\mathrm{CP}$ using a structured questionnaire developed by the researchers. Children and adolescents (0-18 years old) with $\mathrm{CP}$ who were diagnosed prior to the time of collection (CID10: G80.0G80.9) were included. Those who did not live in the municipality and cases that were also present in the specialized data were excluded.

\section{Statistical analysis}

The period prevalence of $\mathrm{CP}$ was calculated (Braun et al., 2015). We proposed a sample of 1,000 children and adolescents living in each neighbourhood to calculate the prevalence rate. Data of the residents were obtained from the IBGE (IBGE, 2018).

The Health Vulnerability Index (HVI) was considered in the analyses as a compound variable. Based on a previous study conducted in Brazil (Drachler et al., 2014), the HVI was developed as a synthetic index using Principal Component Analysis that groups 10 variables related to 3 dimensions (Demographic, Socioeconomic, and Infrastructural). HVI scores were reported for each neighbourhood on a scale ranging from low vulnerability (0) to high vulnerability (1). The variable dimensions were the following:

\section{Demography}

i) Percentage of children under 5 years of age in the population;

ii) Percentage of brown or black people.

\section{Socioeconomy}

iii) Percentage of households with per capita income of up to $1 / 2$ minimum wage;

iv) Average income of heads of household;

v) Percentage of women heads of household with a monthly nominal income of up to $1 / 2$ minimum wage;

vi) Percentage of non-literate persons aged $8-15$ years;

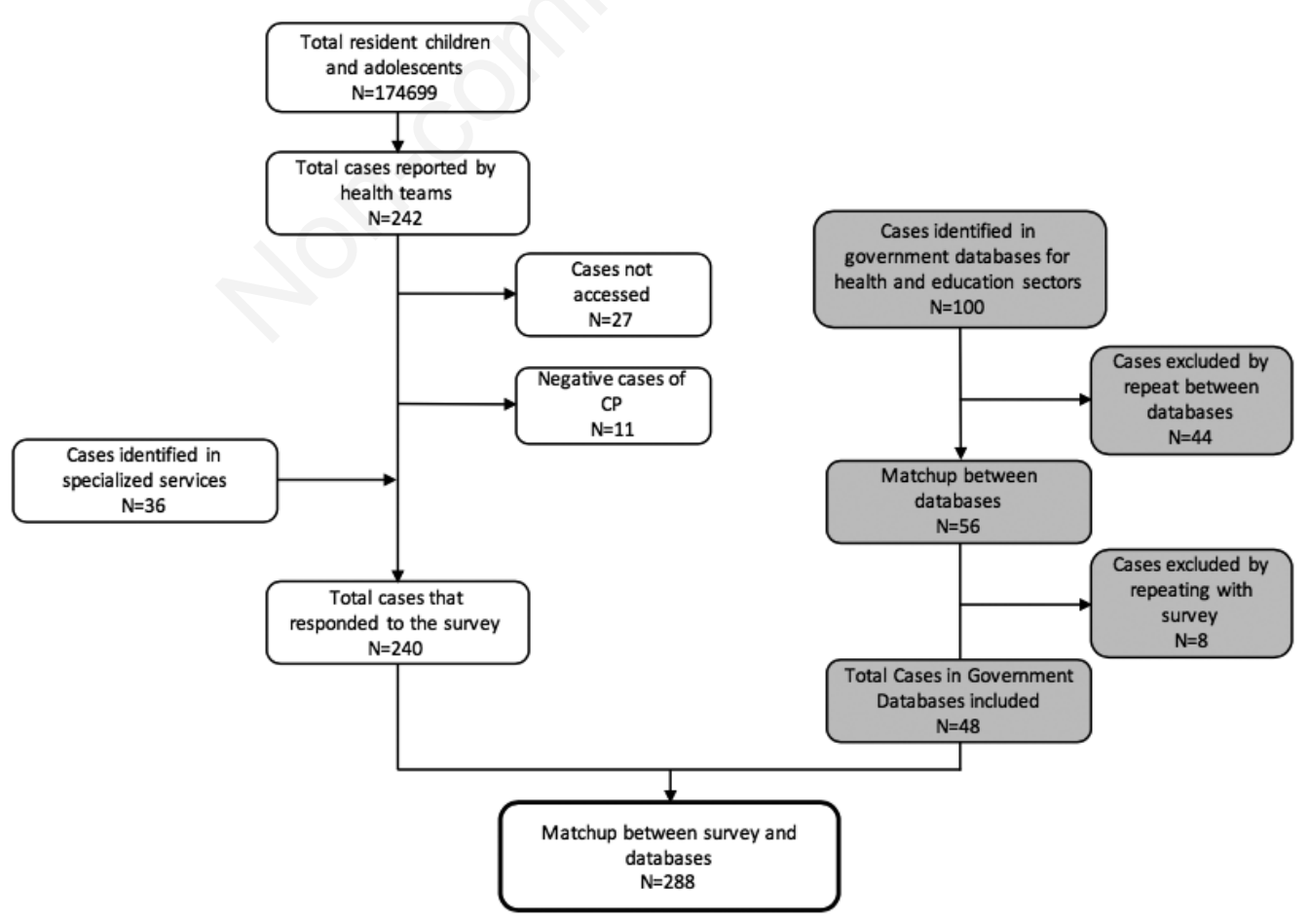

Figure 1. Flowchart of data production of children and adolescents with cerebral palsy in Aracaju, Sergipe, Brazil. 
vii) Percentage of children living in households where none of the residents completed elementary education.

\section{Infrastructure}

viii) Percentage of households with water supply not connected to the distribution network;

ix) Percentage of households with inadequate sanitary sewage; 10. Percentage of households with no garbage collection service.

The Exploratory Analysis of Spatial Data (EASD) technique was used to describe spatial distributions (clusters or dispersions) in patterns of global and local spatial associations (Ministério da Saúde, 2007). An array of weights was created using the Queen Contiguity criterion among the 39 neighbourhoods analyzed by considering the neighbourhood of first order. The CP distribution by neighbourhood was determined using period prevalence rates and an empirical Bayesian model, whose estimator is a way of reducing the fluctuation associated with small samples. The weighting is performed using the average rate of neighbours (Anselin 2005).

The Global and Bivariate Local Moran's Index was used to identify the spatial correlation between CP and HVI, indicating the regions with characteristic patterns associated with geographical location. The Global Moran's Index may have positive values (between 0 and 1) indicating a direct correlation, negative values (between 0 and -1), indicating an inverse correlation, and a zero value indicating spatial independence (Anselin 2005). Moran's Local Bivariate analysis showed four types of spatial relationships (corresponding to the Moran scatter diagram) between the two variables proposed, considering a place unit and neighbouring units describing high prevalence of $\mathrm{CP}$ and high HVI as High-High (HH), high prevalence of CP and low HVI as High-Low (HL), low prevalence of $\mathrm{CP}$ and high HVI as Low-High (LH), and low prevalence of CP and low HVI as Low-Low (LL). Linear regression analysis was used to demonstrate the association between the prevalence of CP and the Health Vulnerability Score of neighbourhoods. Values with $\mathrm{p}<0.05$ were considered significant.

The statistical analyses were carried out using QGIS software version 2.18.3 (Creative Commons Attribution ShareAlike 3.0 license CC BY-SA, Las Palmas, CA, USA) and GEODA software version 1.12 (Spatial Analysis Laboratory, University of Illinois, Urbana Champaign, USA). The cartographic base of the city of Aracaju was provided by IBGE (IBGE, 2018). The cartographic projection followed the SIRGAS 2000 geodetic reference system.

\section{Results}

Out of the total 174,699 children and adolescents living in the neighbourhoods under study, 288 with $\mathrm{CP}$ were included. The prevalence of CP was $1.65 / 1,000$. The differences among city neighbourhoods varied from $0-4 / 1,000$. The distribution of CP by neighbourhood according to gross prevalence rate $(2 \mathrm{~A})$, and the prevalence rate reduced by the empirical Bayesian model (2B), is shown as choropleth maps (Figure 2). Visual examination of the maps showed a higher prevalence in the northern part of the city and lower prevalence in the central region. The mean age of the population with $\mathrm{CP}$ was 9 years, 1 month ( $\mathrm{SD}=5$ years, 2 months). Table 1 categorizes the study population according to gender and age groups.

The results suggested that the areas of higher prevalence and vulnerability are not randomly distributed. We observed a correlation between areas with a higher prevalence of CP and areas with higher HVI scores supported by the Global Bivariate Moran's test ( $\mathrm{I}=0.37, p=0.001$ ) revealed two $\mathrm{HH}$ cluster areas representing a higher prevalence of $\mathrm{CP}$ associated with a higher HVI score, one in the northern end of the city and another in the southern region (Figure 3). The neighbourhoods of the central region formed an LL cluster suggesting that the less vulnerable area had a lower prevalence of CP. An HL outlier was seen in the central region suggesting distancing from the neighbourhood. This was considered significant $(\mathrm{p}<0.05)$.

Linear regression analysis also suggested that increased HVI scores contributed to the increased CP prevalence (Figure 4). However, the coefficient of determination was low. There was no need to apply spatial regression techniques since the model met the normality assumptions as confirmed by the Jarque-Bera test ( $p=$ $0.51)$ and homoscedasticity as confirmed by the Breusch-Pagan ( $p$ $=0.11)$ and Koenker-Bassett $(p=0.07)$ tests. The Moran's Index and Lagrange multipliers for the residues were not significant $(p>0.05)$, suggesting that there was no autocorrelation of regres-

Table 1. Distribution of children and adolescents with cerebral palsy according to gender and age.

\begin{tabular}{lcc} 
Variable & No. & $\%$ \\
Sex & & \\
Male & 163 & 56.5 \\
Female & 125 & 53.5 \\
Age (year) & & \\
$0-4$ & 64 & 22.22 \\
$5-8$ & 65 & 22.57 \\
$9-12$ & 72 & 25.00 \\
$13-16$ & 60 & 20.83 \\
$17-18$ & 27 & 9.38 \\
\hline Total & $\mathbf{2 8 8}$ & $\mathbf{1 0 0 . 0 0}$
\end{tabular}

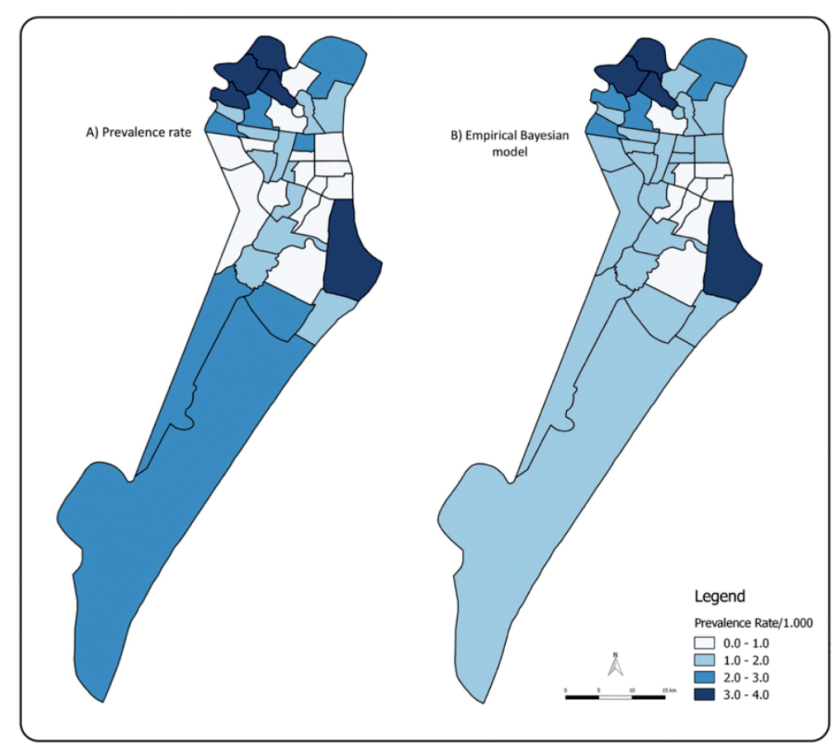

Figure 2. Maps representing the spatial distribution of cerebral palsy in Aracaju, Sergipe, Brazil, 2018 (A) and the gross prevalence rate per $1,000(B)$. Prevalence rate reduced by the empirical Bayesian model. 
sion residues among the neighbourhoods, indicating that the association in one neighbourhood occurred independently of the association in surrounding neighbourhoods.

\section{Discussion}

We found a lower CP prevalence rate $(1.65 / 1,000)$ than in most other countries including high-income countries such as the USA $(2.9 / 1,000)$ and in European countries $(1.77 / 1,000)$ (Durkin et al., 2016; Sellier et al., 2016). A meta-analysis of the CP prevalence including 19 studies, with 16 surveys conducted in high-income countries, found an worldwide average CP prevalence of 2.11/1,000 live births (Oskoui et al., 2013). Studies conducted in low and middle-income socioeconomic areas similar to Brazil also showed a higher CP prevalence. For example, a survey conducted in China, in which most of the participants were males, showed a prevalence of 2.8/1,000 children, and a population-based survey conducted in Uganda showed a prevalence of 2.9/1,000(KakoozaMwesige et al., 2017; Tseng et al., 2018). The low prevalence rate in the present study can be attributed to undiagnosed cases or a high mortality rate. It is unlikely that the emigration of patients with CP contributes to the prevalence rate since Aracaju City has more resources for treatment and rehabilitation than any other in the State. The differences within the city were relevant, since some neighbourhoods had a prevalence three to four times greater than others, revealing that the total prevalence rate is not a homogeneous indicator.

Exploratory analysis of the maps, spatial correlation tests and linear regression results confirmed that the spatial distribution of high vulnerability and that of $\mathrm{CP}$ were associated with spatial cluster formation, which shows that the prevalence of $\mathrm{CP}$ is associated with the contextual health inequities revealed by HVI. These results show similarity with two papers that found and association between $\mathrm{CP}$ and socioeconomic factors through composite indices of deprivation (Dolk et al., 2006; Oskoui et al., 2016). One of the studies, conducted in England, reported that the risk of post-neonatal CP was $86 \%$ higher in the poorest quintile of the population (Dolk et al., 2010), while a Canadian study revealed that the use of the composite index improved the comparability of the findings and that socioeconomic contextual factors may imply greater risk and severity of CP (Oskoui et al., 2016). This is supported by a study conducted in the north of England, aimed at reporting spatiotemporal grouping among $\mathrm{CP}$ cases, that found results consistent with exposure to maternal infections during the perinatal period, with such clusters found in densely populated areas (McNally and Colver, 2008).

Other studies associated health problems during gestation and low birth weight with areas of socioeconomic deprivation thereby demonstrating spatial dependence (Charreire and Combier, 2009; Chong et al., 2013; de Miranda et al., 2014; Insaf and Talbot, 2016). These investigations support the importance of this kind of research. Indeed, further investigation of certain spatial CP clusters might lead to a better understanding of other maternal and child health problems. The use of HVI was a relevant alternative to the traditional ways of measuring associations with socioeconomic status that focus only on income or education. HVI encompasses a set of demographics and socioeconomic and infrastructure variables that interact with one another and affect the daily life of people in complex ways.

Social vulnerability is associated with local inequalities,

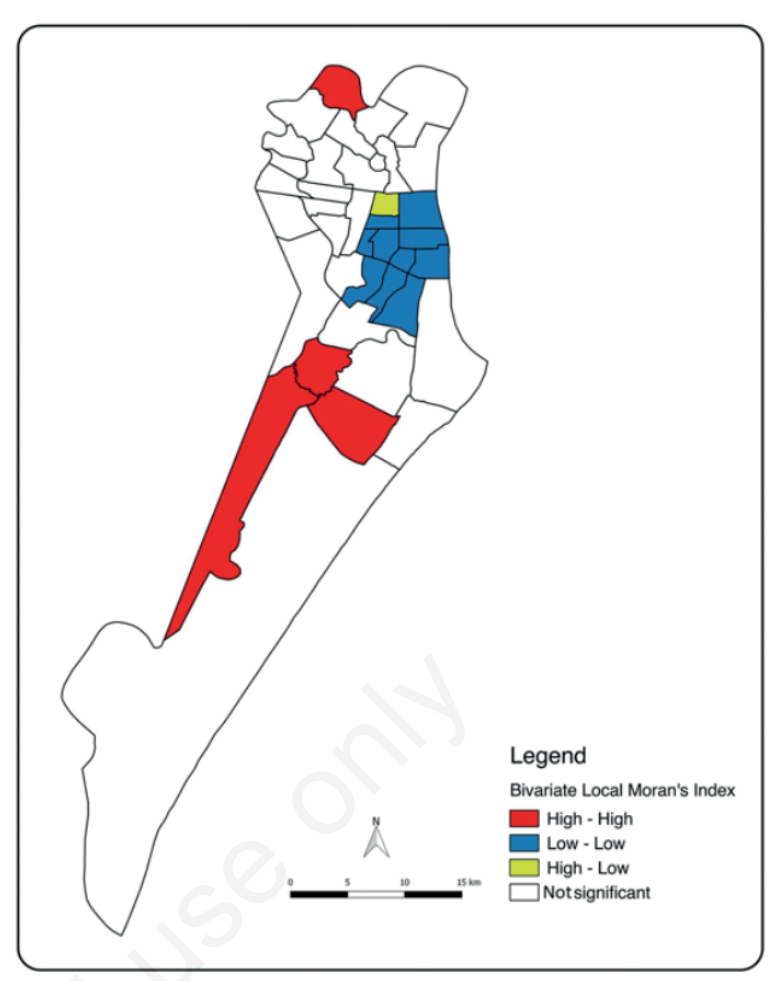

Figure 3. Prevalence of cerebral palsy and the Health Vulnerability Index based on bivariate Local Moran's Index by neighbourhood in Aracaju, Sergipe, Brazil.

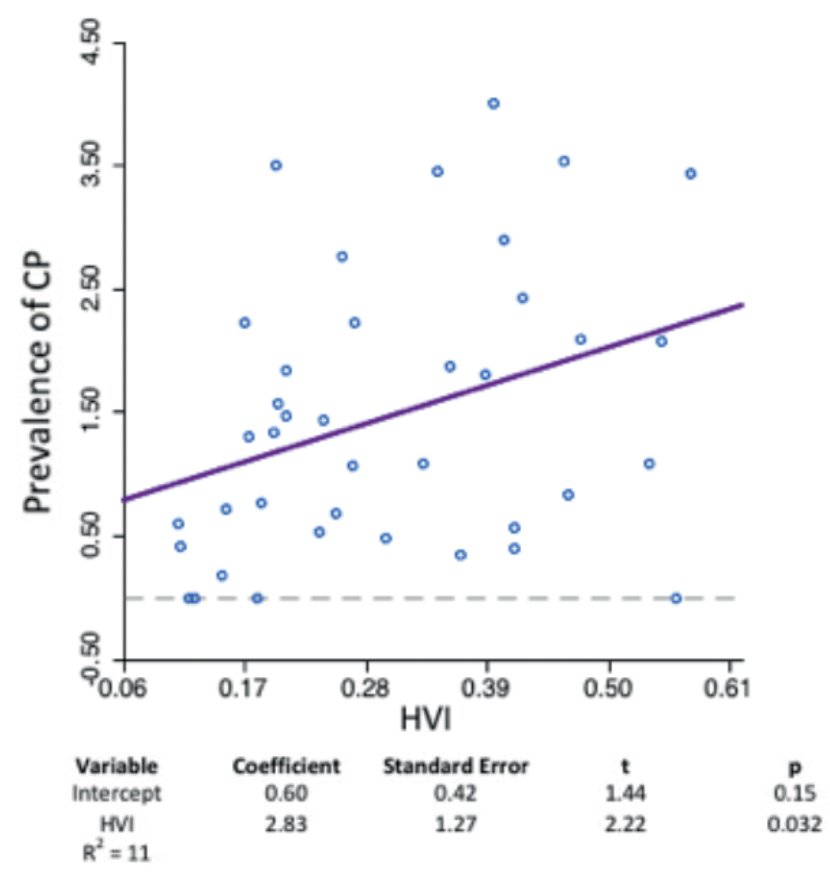

Figure 4. Prevalence rates of cerebral palsy and the Health Vulnerability Index based on linear regression scatter plot by neighbourhood in Aracaju, Sergipe, Brazil 
including the characteristics of communities, the built environment, the level of urbanization, growth rates and economic vitality. These are social factors that influence or shape the susceptibility of various groups and their ability to respond (Cutter et al., 2003). Socioeconomic aspects may influence the opportunities for education, housing, nutrition, health behaviour and healthcare. A study on health vulnerability states that human well-being is a result of the wider political, economic, social and ecological context and that structural inequities lead to disparities in individual health (Tallman, 2016). We must consider that inequities can lead to CP, just as $\mathrm{CP}$ can lead to inequities, since families may become impoverished as a result of the costs associated with this disability (WHO, 2011). Knowledge of the spatial distribution of health events has great relevance for cluster identification, formulation of hypothetical etiological factors, association with contextual environmental factors as well as issues related to socioeconomy and demography. According to Waldo Tobler's First Law of Geography (Tobler, 1970), "everything is related to everything else, but near things are more related than distant things."

Studies such as this can contribute to the formulation, implementation, and evaluation of interventions aimed at reducing CP's risk and impact factors. The effectiveness of interventions for the primary prevention of CP needs to be monitored in terms of reduction or exacerbation of socioeconomic inequalities (Dolk et al., 2001). A systematic review of the economic aspects of CP states that prevention is the most cost-effective intervention measure (Shih et al., 2018).

This study has some limitations. Despite being an association study, it did not specifically determine the interaction with risk factors or isolated aspects of individual exposure. However, one redeeming features of this study is that our sample representativeness was not restricted to participants who use rehabilitation services. It is known that the greatest impact in health caused by $\mathrm{CP}$ is felt by children who are not outpatients (Oskoui et al., 2016). We also wish to emphasize that studies using spatial analysis as a tool to understand the epidemiology of CP are lacking.

\section{Conclusion}

Spatial data analysis using GIS is relevant to the epidemiological understanding of $\mathrm{CP}$ and can guide policymakers in decisionmaking for the production, distribution and regulation of health and services at the local level. One important finding is that the distribution of $\mathrm{CP}$ in the study population was not homogeneous throughout the territory as some CP clusters were associated with areas of high socioeconomic vulnerability.

\section{References}

Anselin L, 2005. Exploring Spatial Data with GeoDa: A Workbook. Geography 244.

Braun KN, Maenner MJ, Christensen D, Doernberg NS, Durkin MS, Kirby RS, 2015. The role of migration and choice of denominator on the prevalence of cerebral palsy. Dev Med Child Neurol 55:520-6.

Charreire H, Combier E, 2009. Poor prenatal care in an urban area: A geographic analysis. Heal Place 15:412-9.

Chi W, Wang J, Li X, Zheng X, Liao Y, 2008. Analysis of geographical clustering of birth defects in Heshun county, Shanxi province. Int J Environ Health Res 18:243-52.

Chong S, Nelson M, Byun R, Harris L, Eastwood J, Jalaludin B, 2013. Geospatial analyses to identify clusters of adverse antenatal factors for targeted interventions. Int J Health Geogr 12:1-10.

Colver A, Fairhurst C, Pharoah POD, 2014. Cerebral palsy. Lancet 383:1240-9. doi: 10.1016/S0140-6736(13)61835-8.

Cutter SL, Boruff BJ, Shirley WL, 2003. Social Vulnerability to Environmental Hazards n. Soc Sci Q 84:242-61. doi: 10.1111/1540-6237.8402002.

de Miranda MJ, Costa C, Santana P, Barrozo LV, 2014. [Associação espacial entre variáveis socioeconômicas e risco relativo de nascimentos pré-termo na Região Metropolitana de São Paulo ( RMSP ) e na Área Metropolitana de Lisboa ( AML ).] Saude Soc 23:1142-53. doi: 10.1590/S010412902014000400002. [Article in Portiguese].

Dolk H, Parkes J, Hill N, 2006. Trends in the prevalence of cerebral palsy in Northern Ireland, 1981-1997. Dev Med Child Neurol 48:406-12. doi: 10.1017/S0012162206000909.

Dolk H, Pattenden S, Bonellie S, Colver A, King A, Kurinczuk JJ, et al., 2010. Socio-economic inequalities in cerebral palsy prevalence in the United Kingdom: a register-based study. Paediatr Perinat Epidemiol 24:149-55. doi: 10.1111/j.13653016.2009.01083.x

Dolk H, Pattenden S, Johnson A, 2001. Cerebral palsy, low birthweight and socio-economic deprivation: inequalities in a major cause of childhood disability. Paediatr Perinat Epidemiol 15:359-63. doi: 10.1046/j.1365-3016.2001.00351.x.

Drachler M de L, Lobato MA de O, Lermen JI, Fagundes S, Ferla AA, Drachler CW, et al., 2014. Desenvolvimento e validação de um índice de vulnerabilidade social aplicado a políticas públicas do SUS. Cien Saude Colet 19:3849-58. doi: 10.1590/1413-81232014199.12012013.

Durkin MS, Benedict RE, Christensen D, Dubois LA, Fitzgerald RT, Kirby RS, et al., 2016. Prevalence of Cerebral Palsy among 8-Year-Old Children in 2010 and Preliminary Evidence of Trends in Its Relationship to Low Birthweight. Paediatr Perinat Epidemiol 30:496-510. doi: 10.1111/ppe.12299.

Graham HK, Rosenbaum P, Paneth N, Dan B, Lin J-P, Damiano DL, et al., 2016. Cerebral palsy. Nat Rev Dis Prim 2:15082. doi: https://doi.org/10.1038/nrdp.2015.82.

IBGE, 2018. Instituto Brasileiro de Geografia e Estatística (IBGE). Available from: https://www.ibge.gov.br/

Insaf TZ, Talbot T, 2016. Identifying areas at risk of low birth weight using spatial epidemiology: A small area surveillance study. Prev Med (Baltim) 88:108-14. doi: 10.1016/j.ypmed. 2016.03.019

Kakooza-Mwesige A, Andrews C, Peterson S, Wabwire Mangen F, Eliasson AC, Forssberg H, 2017. Prevalence of cerebral palsy in Uganda: a population-based study. Lancet Glob Heal 5:e1275-82. doi: 10.1016/S2214-109X(17)30374-1.

Kirby RS, Delmelle E, Eberth JM, 2017. Advances in spatial epidemiology and geographic information systems. Ann Epidemiol 27:1-9. Available from: doi: 10.1016/j.annepidem.2016.12.001

Liao Y, Zhang Y, He L, Wang J, Liu X, Zhang N, et al., 2016. Temporal and spatial analysis of Neural tube defects and detection of geographical factors in Shanxi Province, China. PLoS One 11:1-14.

McIntyre S, Taitz D, Keogh J, Goldsmith S, Badawi N, Blair E, 2013. A systematic review of risk factors for cerebral palsy in 
children born at term in developed countries. Dev Med Child Neurol 55:499-508.

McNally RJQ, Colver AF, 2008. Space-time clustering analyses of occurrence of cerebral palsy in Northern England for births 1991 to 2003. Ann Epidemiol 18:108-12. doi: 10.1016/j.annepidem.2007.07.104.

Ministério da Saúde, 2007. Brasil. Introdução à Estatística Espacial para Saúde Pública. Volume 3. Brasília-DF: Ministério da Saúde. Secretaria de Vigilância em Saúde.

Oskoui M, Coutinho F, Dykeman J, Jetté N, Pringsheim T, 2013. An update on the prevalence of cerebral palsy: A systematic review and meta-analysis. Dev Med Child Neurol 55:509-19.

Oskoui M, Messerlian C, Blair A, Gamache P, Shevell M. 2016. Variation in cerebral palsy profile by socio-economic status. Dev Med Child Neurol 58:160-6.

Sellier E, Platt MJMJ, Andersen GLGL, Krägeloh-Mann I, De La Cruz J, Cans C, et al., 2016. Decreasing prevalence in cerebral palsy: A multi-site European population-based study, 1980 to 2003. Dev Med Child Neurol 58:85-92. doi: 10.1111/ dmcn.12865.
Shih STF, Tonmukayakul U, Imms C, Reddihough D, Graham HK, Cox L, et al., 2018. Economic evaluation and cost of interventions for cerebral palsy: a systematic review. Dev Med Child Neurol 60:543-58. doi: 10.1111/dmcn.13653.

Solaski M, Majnemer A, Oskoui M, 2014. Contribution of socioeconomic status on the prevalence of cerebral palsy: a systematic search and review. Dev Med Child Neurol 56:1043-51.

Tallman PS, 2016. The Index of Vulnerability: An anthropological method linking social-ecological systems to mental and physical health outcomes. Soc Sci Med 2016;162:68-78. doi: 10.1016/j.socscimed.2016.06.016

Tobler WR, 1970. A Computer Movie Simulating Urban Growth in the Detroit Region. Economic Geography 46:234-240.

Tseng S-H, Lee J-Y, Chou Y-L, Sheu M-L, Lee Y-W, 2018. Association between socioeconomic status and cerebral palsy. Papadelis C, editor. PLoS One 13:e0191724. doi: 10.1371/ journal.pone.0191724.

WHO, 2011. World report on disability. Available from: https:/www.who.int/publications/i/item/world-report-on-disability 